\title{
Adolescent Problem Behavior in Nairobi's Informal Settlements: Applying Problem Behavior Theory in Sub-Saharan Africa
}

Robert P. Ndugwa, Caroline W. Kabiru, John Cleland, Donatien Beguy, Thaddeus Egondi, Eliya M. Zulu, and Richard Jessor

\begin{abstract}
Adolescent involvement in problem behaviors can compromise health, development, and successful transition to adulthood. The present study explores the appropriateness of a particular theoretical framework, Problem Behavior Theory, to account for variation in problem behavior among adolescents in informal settlements around a large, rapidly urbanizing city in sub-Saharan Africa. Data were collected from samples of never married adolescents of both sexes, aged 12-19, living in two Nairobi slum settlements $(N=1,722)$. Measures of the theoretical psychosocial protective and risk factor concepts provided a substantial, multi-variate, and explanatory account of adolescent problem behavior variation and demonstrated that protection can also moderate the impact of exposure to risk. Key protective and risk factors constitute targets for policies and programs to enhance the health and well-being of poor urban adolescents in sub-Saharan Africa.
\end{abstract}

KEYWORDS Problem behavior theory, Multiple problem behaviors, Protective factors, Risk factors, Moderator effects, Adolescents, Informal settlements, Slums,

Slum settlements, Kenya

\section{INTRODUCTION}

Although adolescence provides a challenging developmental period for young people throughout the world, the difficulties faced by young people in developing countries are often exacerbated by poverty, limited access to education, and unstable social contexts. Such circumstances can constitute pressures toward engaging in problem behaviors; that is, behaviors that transgress societal norms and that can compromise adolescent health and development.

Much of the literature on adolescent problem behavior has come from western societies, and theories about adolescent problem behaviors have largely been tested on adolescents living in those settings. ${ }^{1-4}$ A conceptual framework or theory that, while developed in the United States, has been applied in both developed and developing countries, is Jessor's Problem Behavior Theory. ${ }^{1,5-8}$ To our knowledge, however, Problem Behavior Theory has not yet been widely employed to account for

Ndugwa and Cleland are with the Centre for Population Studies, London School of Hygiene and Tropical Medicine, London, UK; Kabiru, Beguy, and Egondi are with the African Population and Health Research Centre, Nairobi, Kenya; Zulu is with the African Institute for Development Policy Research and Dialogue, Nairobi, Kenya; Jessor is with the Institute of Behavioral Science, University of Colorado at Boulder, Colorado, USA.

Correspondence: Robert P. Ndugwa, Centre for Population Studies, London School of Hygiene and Tropical Medicine, London, UK. (E-mail: robert.ndugwa@lshtm.ac.uk) 
variation in problem behavior among young people in sub-Saharan Africa, more particularly those that live in urban informal settlements (commonly called slum settlements) and are exposed to the extreme poverty and dangers that characterize such settings. In this study, we explore the applicability of Problem Behavior Theory as an explanation of problem behavior among adolescents in two slum settlements in Nairobi, Kenya.

\section{Problem Behavior Theory}

Problem Behavior Theory describes the relations of psychosocial protective and risk factors to involvement in various adolescent problem behaviors such as delinquency, tobacco use, alcohol abuse, other illicit drug use, early sexual intercourse,

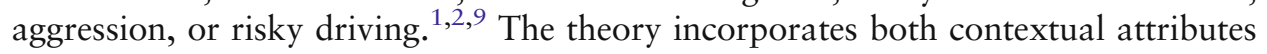
and individual characteristics conceptualized as protective factors and risk factors. The explanatory model takes into account both the direct effects of protective factors and risk factors as well as the moderating or buffering effect that protection may have on the impact of exposure to risk. In a large number of studies, psychosocial risk and protective factors have been shown to account for substantial amounts of variation in adolescent problem behavior for both males and females, for younger and older adolescents, and across groups varying in socioeconomic status, race, and ethnicity. ${ }^{8-11}$

Three types of protective factors (models protection, controls protection, and support protection) and three types of risk factors (models risk, opportunity risk, and vulnerability risk) are specified in the theory. According to the theory, the greater the risk factors and the less the protective factors in an adolescent's life situation, the greater the likelihood of an adolescent's involvement in problem behavior. ${ }^{9}$ Only a few studies have tested the cross-national applicability of the theory. One such study tested the theory among adolescents in China and the United States and showed that the model was able to account for substantial variation in problem behavior in both countries, even though problem behaviors were more prevalent among US than Chinese adolescents. ${ }^{6}$ In addition, a recent comparative study among Georgian and Swiss youth also supported the applicability of the theory beyond the United States borders. ${ }^{12}$ Few studies, however, have tested the applicability of the theory within less developed countries like Kenya, and more so in an increasingly important population of urban youth.

\section{Kenya and Urban Informal Settlements}

Urban informal settlements (commonly referred to as slums or slum settlements), are characterized by congestion, high levels of unemployment, inadequate social services, extreme poverty, insecurity, crime, and hopelessness, and, therefore, offer a unique setting to study adolescent problem behavior. ${ }^{13,14}$ Slum settlements are largely the result of rapid urbanization amidst declining economies and poor governance. $^{13,14}$

Kenya is a typical example of a country where rapid urbanization and social change have continued unabated. In Nairobi, the capital city, over half of the residents live in slum settlements or slum-like conditions, without proper access to sanitation or affordable clean water. ${ }^{13,15}$ The informal classification of slum settlements has for long justified the unwillingness or inability of governments and local councils to provide formal health, education, and social services to residents of slum settlements. This has had large impacts on health and social outcomes among dwellers of slum settlements. For example, the HIV prevalence among adults in the 
slum settlements aged $15-49$ is estimated to be about $11.5 \%{ }^{16}$ compared to $9.9 \%$ among the same age group for Nairobi City as a whole. ${ }^{17}$ Other socioeconomic and health indicators of slum settlements are not any better; for example, there are large differences in educational attainment or access to educational resources, levels of teacher absenteeism and large disparities in the quality of schools in slum settlements compared to non-slum areas. ${ }^{18}$ Consequently, while $90 \%$ of children living in low income but non-slum areas transition from primary to secondary school, only $40 \%$ of their counterparts in slum areas do so. ${ }^{18}$ Indeed, poverty coupled with lack of formal education and livelihood opportunities among young people in slum settings has been shown to be associated with an increased risk of involvement in anti-social behaviors, drug abuse, risky sexual behaviors, and a higher likelihood of dropping out from school. ${ }^{18-22}$ The above risk factors have been found to play a significant role in increasing the incidence of HIV/AIDS among adolescents in sub-Saharan Africa. ${ }^{23,24}$ For slum adolescents, the challenges they face are further compounded by lack of access to proper health services. ${ }^{25}$

Since urbanization is projected to increase in developing countries, ${ }^{13,15}$ an understanding of factors that reduce risky behaviors and enhance protection among adolescents is key to developing policies that can enhance well-being among adolescents living in poor urban settings. Problem behavior can be understood by applying existing theoretical frameworks. In this paper, we examine the applicability of Problem Behavior Theory and explore the contribution that psychosocial protection and risk factors can make to explaining problem behavior among adolescents aged 12-19 in two informal settlements in Nairobi city.

\section{DATA AND METHODS}

\section{Study Design, Participants, and Procedures}

This paper draws on data collected under two research projects nested to the Nairobi Urban Health and Demographic Surveillance System (NUHDSS). These are the Transition-To-Adulthood (TTA) project and the Education Research Program (ERP). In 2008, the NUHDSS mid-year population was 59,570 people living in 24,100 households located in Korogocho and Viwandani slum settlements in Nairobi city. The NUHDSS, TTA and ERP have ethical approval from the Kenya Medical Research Institute's ethical review board. In addition, all research staff, fieldworkers, and data processors are trained on research ethics. For all studies, potential respondents are first briefed on the study objectives and then invited to participate. Respondents are requested to give verbal or signed consent; for respondents aged 12-17, consent is also requested from their parents or guardians.

\section{The Transition-To-Adulthood project}

TTA is a component of the 5-year Urbanization, Poverty and Health Dynamics research program conducted by the African Population and Health Research Center. The TTA's general objective is to identify protective and risk factors in the lives of adolescents growing up in these two informal settlements in Nairobi and to examine how these factors influence their transition to adulthood. Adolescents were randomly selected within the households in the study area using records of residents in the NUHDSS for the year 2007. Allowing for an annual attrition rate of $16 \%$ for Korogocho and 24\% for Viwandani, and given the planned 3-year follow-up, 2,478 and 3,028 randomly selected young people were targeted for recruitment from 
Korogocho and Viwandani, respectively. Between October 2007 and June 2008, about 4,058 (75\% response rate) adolescents aged 12-21 were interviewed. A structured questionnaire was administered by interviewers and included questions covering reproductive aspirations (e.g., parenthood, marriage); key health and other concerns (e.g., worry about HIV/AIDS, getting a job, marriage, finishing school, employment); living arrangements and nature of interactions with parents, guardians, teachers, and peers; involvement in youth groups (e.g., religious and social groups); and involvement in risky behaviors (e.g., early sexual debut and delinquency). The complete questionnaire was translated from English to Swahili and administered in Swahili, the language most spoken in the study area.

\section{The Education Research Program}

This is a longitudinal study designed to compare educational outcomes between two slum settlements (Korogocho and Viwandani) and two non-slum communities (Harambee and Jericho) in Nairobi city. The ERP has been interviewing all children aged 5-21 years since 2005 using five modular interviewer-administered questionnaires that collect information on household characteristics, school characteristics, school enrolment, and children's behavior. ${ }^{26}$ Information on adolescent sexual and other risk behaviors is collected as part of the module that assesses children's schooling status and experiences, as well as informal training and apprenticeships. The behavior section of the module is completed by respondents aged at least 12 years, and the section must be completed with the child as the respondent. By December 2008, a baseline survey and four waves of data collection were completed by the ERP. Wave 4 was collected from December 2007 to August 2008. Details of the sample design and other survey procedures are available elsewhere. ${ }^{26}$

\section{Description of the Merged Sample}

As both the ERP and the TTA are nested to the NUHDSS, it is possible to merge information collected around the same time from the same individuals by the two studies. The merged file would contain detailed information on risk and protective factors from the TTA and details relating to schooling and substance use from the ERP. We merged data from the TTA and ERP Wave 4 collected between October 2007 and August 2008 using the unique identification numbers that are assigned to all residents in the NUHDSS. Overall, 2,028 respondents aged 12-21 years were found in both the ERP and the TTA databases. In order to provide a better comparison with other studies, the adolescents aged 12-19 years were selected and since involvement in sexual relations was used as one of the measures for problem behavior, we excluded adolescents who were or had ever been married. The final sample had 1,722 never married adolescents. To rule out 'selection bias', the characteristics of this sample were compared to the larger ERP and TTA primary samples and were generally comparable for several selected characteristics (gender, age, slum location, parental co-residence, education status). The age group 12-19 is wide and covers adolescents at markedly different stages of their maturation. This was evident in the differences in prevalence of problem behaviors by age. Hence, adolescents were grouped into two age cohorts (12-14 and 15-19 years) for this study. Socio-demographic characteristics of the sample and the prevalence of problem behaviors are presented in Table 1.

Socio-demographic variables used in the analysis were: age in years (continuous); sex (male and female); household size; study site (Korogocho and Viwandani); duration of stay in the study area; parental co-residence (staying alone, with both 
TABLE 1 Descriptive characteristics of study participants and prevalence of problem behaviors by age-cohort

\begin{tabular}{|c|c|c|c|}
\hline Characteristics & $12-14$ years $(n=780)$ & $15-19$ years $(n=942)$ & $\begin{array}{l}\text { Total } \\
(N=1,722)\end{array}$ \\
\hline \multicolumn{4}{|l|}{ Slum site (\%) } \\
\hline Korogocho & 47.8 & 57.2 & 53.0 \\
\hline Viwandani & 52.2 & 42.8 & 47.0 \\
\hline \multicolumn{4}{|l|}{$\operatorname{Sex}(\%)$} \\
\hline Male & 50.8 & 54.5 & 52.8 \\
\hline Female & 49.2 & 45.5 & 47.2 \\
\hline \multicolumn{4}{|l|}{ Parental co-residence (\%) } \\
\hline Stay alone or other & 7.1 & 23.3 & 16.0 \\
\hline With one parent & 27.3 & 28.6 & 28.0 \\
\hline With both parents & 65.6 & 48.1 & 56.0 \\
\hline \multicolumn{4}{|l|}{ Socioeconomic status (\%) } \\
\hline Least wealthy & 41.8 & 41.8 & 41.8 \\
\hline Middle & 31.0 & 27.4 & 29.0 \\
\hline Most wealthy & 27.2 & 30.8 & 29.2 \\
\hline Currently in school (\%) & 95.6 & 63.8 & 78.2 \\
\hline In secondary school or higher (\%) & 1.61 & 54.0 & 24.9 \\
\hline $\begin{array}{l}\text { Median duration of stay } \\
\text { in slum(years) }\end{array}$ & 12 & 15 & 13 \\
\hline $\begin{array}{l}\text { Ever been pregnant or made } \\
\text { someone pregnant (\%) }\end{array}$ & 0.3 & 4.0 & 2.3 \\
\hline Ever drunk alcohol (\%) & 1.7 & 9.7 & 6.0 \\
\hline Had sex before 15 years (\%) & 3.2 & 9.0 & 6.4 \\
\hline Ever had sex (\%) & 3.2 & 24.6 & 15.0 \\
\hline Ever smoked cigarettes (\%) & 0.9 & 4.0 & 2.6 \\
\hline Ever used illicit drugs (\%) & 2.6 & 10.3 & 6.8 \\
\hline Ever started a fight with peers (\%) & 34.4 & 33.8 & 34.1 \\
\hline $\begin{array}{l}\text { Ever hit or threatened to hit } \\
\text { someone (\%) }\end{array}$ & 27.2 & 25.9 & 26.5 \\
\hline $\begin{array}{l}\text { Ever tried to take something } \\
\text { belonging to others }(\%)\end{array}$ & 22.6 & 19.4 & 20.8 \\
\hline
\end{tabular}

\footnotetext{
${ }^{a}$ Base is currently in school.
}

parents, with one of either parent, or with other relative or non-relative); and schooling status (in school versus out of school). Socioeconomic status was assessed using a three-category wealth index (least wealthy, middle, and most wealthy) constructed using household assets and amenities collected through the NUHDSS in 2007. These included asset ownership (e.g., radio, television set, motorcycle, mattress, kerosene lamp, phone, and sewing machine), building materials (floor material, roof, wall material) and availabilities of amenities (water supply, electricity), etc. Principal components analysis was used to construct the socioeconomic index. ${ }^{27}$

About $53 \%$ of the participants were living in Korogocho and about $47 \%$ resided in Viwandani. More than half of all the adolescents reported living with both parents $(56 \%)$, while $28 \%$ were living with one of the parents and $16 \%$ were living alone or with other people (relatives or non-relatives). As expected, the proportion of adolescents living with no parent was higher in the older age cohort. About $78 \%$ of the adolescents indicated that they were currently in school, with the vast 
majority of the younger cohort $(95.6 \%)$ versus close to two-thirds of the older ones being in school. Of the older cohort (more or less secondary going ages) who were in school, 54\% were in secondary school.

With regard to problem behavior, few adolescents had ever been pregnant or made someone pregnant $(2.3 \%)$, while about $6.4 \%$ reported having had sexual intercourse before reaching 15 years. Older adolescents reported higher levels of involvement in early sexual activity, ever being pregnant or having made someone pregnant, and drinking alcohol than the younger ones (see Table 1).

\section{Measuring Problem Behavior}

A composite eight-item Multiple Problem Behavior Index (MPBI) was constructed assessing delinquent behaviors (three items), early sexual experience (one item), illicit drug use (two items), alcohol consumption (one item), and tobacco smoking experience (one item). Although premarital sexual behavior may not be a problem behavior per se, early sexual activity is problematic because of the adverse health and socioeconomic consequences associated with it, and there are societal pressures to preserve young people's virginity until marriage or as long as possible. Campaigns to promote abstinence and discussion of health consequences of early initiation of sex have especially been highlighted in the widespread HIV prevention programs for adolescents. Therefore, early sexual intercourse was included as a component of the MPBI, with early sexual experience defined as sex before the age of 15 years. This arbitrary cut-off age is a good representation of the median age at first sex for young people growing up in slum settlements. ${ }^{21}$ Using this cut-off, early sexual experience among adolescents aged less than 15 years was equivalent to "Ever had sex (yes/ early sex=1, No/early sex=0)" while for those above 15 years the measure was "whether sex was before reaching 15 years (early sex=1) or after 15 (early sex=0) or never had sex (early sex $=0$ )".

\section{Measuring Protective and Risk Factors}

The three types of protective factors (models, controls, supports) and the two types of risk factors (models and vulnerability) were constructed as composite measures. Opportunity risk, the third type of risk factor had very low variability and was, therefore, dropped from the analysis. Controls protection was measured as two separate sub-composites, one assessing personal (individual-level) controls, and the other informal social controls or social regulation. For adolescents not in school, items in reference to school-related controls or protection were inapplicable to them and were coded as zero at analysis stage. Alpha reliability was used to assess the internal consistency of items for each composite measure. A composite score for each type of theoretical predictor was constructed using standardized values of the individual items in each scale (see Table 2). All the resulting predictors were standardized (to have a mean equal to zero and standard deviation equal to one). This was necessary in order to enable reasonable interpretations of any possible moderator or interaction effects that might emerge in the analyses. As can be seen in Table 2, the alpha reliabilities of the explanatory measures are all acceptable (Cronbach's alpha>0.6), and for four of the six measures reliabilities are good (Cronbach's alpha $>0.7$ ).

\section{Statistical Methods}

Data were analyzed using STATA version $10 .{ }^{28}$ Univariate statistics were computed to describe the respondents' socio-demographic characteristics by age cohort. To 
TABLE 2 Description of items used to construct multiple problem behavior index, protective and risk factor measures

\begin{tabular}{|c|c|c|}
\hline & Items & Response Codes \\
\hline & Multiple Problem Behavior Index & \\
\hline \multirow[t]{2}{*}{1} & Sexual behavior: Have you ever had sexual intercourse? & 1 (Yes), 2 (No) \\
\hline & $\begin{array}{l}\text { How old were you when you first had sexual } \\
\text { intercourse? }\end{array}$ & Age in years \\
\hline $2-5$ & $\begin{array}{l}\text { Substance use: Have you ever used [substance] anytime } \\
\text { in your life? (Drugs: miraa, glue, alcohol, cigarettes) }\end{array}$ & 1 (Yes), 2 (No) \\
\hline \multirow[t]{4}{*}{ 6-8 } & $\begin{array}{l}\text { Delinquent behaviors: How many times have you done } \\
\text { any of the following things in the last } 4 \text { months? }\end{array}$ & \\
\hline & $\begin{array}{l}\text { Starting a fight with your peers? took or tried to take } \\
\text { something that belonged to someone else, without } \\
\text { their knowledge?, hit or threatened to hit a peer or } \\
\text { adult? }\end{array}$ & $\begin{array}{l}0 \text { (Never), } 1 \text { (Once), } 2 \\
\quad \text { (More than once) }\end{array}$ \\
\hline & Social Controls Protection (Cronbach's alpha $=0.83$ ) & \\
\hline & $\begin{array}{l}\text { How much would you say your parents/guardians } \\
\text { really know about the following things about you: }\end{array}$ & \\
\hline $1-9$ & $\begin{array}{l}\text { Where you spend time in the evenings on weekdays? } \\
\text { Who you spend time with in the evenings on week } \\
\text { days? Where you spend time on weekends? Who you } \\
\text { spend time with on weekends? What you do during } \\
\text { your free time? How you spend your money? } \\
\text { Whether you have or do homework? What TV } \\
\text { programs, videos, or films you watch? Who your } \\
\text { friends are? }\end{array}$ & $\begin{array}{l}1 \text { (Never know) to } 3 \\
\text { (Always know) }\end{array}$ \\
\hline $10-11$ & $\begin{array}{l}\text { How often does your parent/guardian scold or repri- } \\
\text { mand you when you do something wrong; for }\end{array}$ & $\begin{array}{l}1 \text { (Never) to } 5 \text { (Every } \\
\text { time) }\end{array}$ \\
\hline
\end{tabular}
example, if you come home late, don't do your chores, watch too much TV? When you do something wrong, how often does your parent/guardian spank or slap you?

If you are currently in school, how important is it to your friends that you do well in school?

13-14 How do most of your friends feel about someone your age drinking alcohol? How do most of your friends feel about someone your age using marijuana or other drugs?

Individual Controls Protection (Cronbach's alpha $=0.66$ )

How important is it to you to rely on religious teaching when you have a problem? How important is it to you to believe in God? How important is it to you to rely on religious beliefs as a guide for day-to-day living? How important is it to be able to turn to prayer when you are facing a personal problem? How important is finishing secondary school? Going to university?

7 How well do you resist peer pressure from the rest of the group?

Please tell me whether you agree or disagree with each statement.

8-9 Young women should remain virgins till they marry? Young men should remain virgins till they marry?

1 (Not too important) to 3 (Very important)

1 (Strongly disapprove) to 4 (Strongly approve)

1 (Not important) to 4 (Very important)

1 (Very well) to 4 (Not well at all)

1 (Agree) 2 (Disagree) 
TABLE 2 Continued

\begin{tabular}{|c|c|c|}
\hline & Items & Response Codes \\
\hline & $\begin{array}{l}\text { Would you say you strongly agree; somewhat agree; } \\
\text { neither disagree nor agree; somewhat disagree; or } \\
\text { strongly disagree with the following statements } \\
\text { about you? }\end{array}$ & \\
\hline $10-13$ & $\begin{array}{l}\text { In general, I like school a lot? I get along well with my } \\
\text { teachers?, I try my best in school?, Doing well in } \\
\text { school is important for my future? }\end{array}$ & $\begin{array}{l}1 \text { (Strongly agree) } 5 \\
\text { (Strongly disagree) }\end{array}$ \\
\hline $1-4$ & $\begin{array}{l}\text { How many of your friends get good marks in school? } \\
\text { How many of your friends participate in sports?, } \\
\text { How many of your friends attend church/mosque?, } \\
\text { How many of your friends want to go to secondary } \\
\text { school/university /college? } \\
\text { Support Protection (Cronbach's alpha = }\end{array}$ & $\begin{array}{l}1 \text { (None of them) to } 4 \\
\text { (All of them) }\end{array}$ \\
\hline $1-4$ & $\begin{array}{l}\text { Since the beginning of this school year, how often has } \\
\text { your (father/father figure) checked your homework or } \\
\text { asked you to make sure you had done it? Since the } \\
\text { beginning of this school year, how often have you } \\
\text { talked to your (father/father figure) about any progress } \\
\text { or problems you were having at school? Since the } \\
\text { beginning of this school year, how often has your } \\
\text { (mother/mother figure) checked your homework or } \\
\text { asked you to make sure you had done it? Since the } \\
\text { beginning of this school year, how often have you } \\
\text { talked to your (mother/mother figure) about any } \\
\text { progress or problems you were having at school? }\end{array}$ & $\begin{array}{l}1 \text { (Never) to } 5 \text { (Almost } \\
\text { every day) }\end{array}$ \\
\hline $5-10$ & $\begin{array}{l}\text { How often does your father/father figure teach you } \\
\text { things you didn't know? How often do you share } \\
\text { secrets or private feelings with your father/father } \\
\text { figure? How often does your father/father figure try } \\
\text { to help you when you need something? How often } \\
\text { does your mother/mother figure teach you things } \\
\text { you didn't know? How often do you share secrets or } \\
\text { private feelings with your mother/mother figure? } \\
\text { How often does your mother/mother figure try to } \\
\text { help you when you need something? }\end{array}$ & $\begin{array}{l}1 \text { (Never) to } 5 \text { (All the } \\
\text { time) }\end{array}$ \\
\hline $11-15$ & $\begin{array}{l}\text { When you are with your girlfriend/boyfriend, you feel } \\
\text { completely able to relax and be yourself. No matter } \\
\text { what happens, you know that your girlfriend/ } \\
\text { boyfriend will always be there for you, You know } \\
\text { that your girlfriend /boyfriend has confidence in } \\
\text { you, Your girlfriend /boyfriend /partner often lets } \\
\text { you know that he/she thinks you are a worthwhile } \\
\text { person. The teachers at my school will spend extra } \\
\text { time to help pupils/students do their best }\end{array}$ & $\begin{array}{c}1 \text { (Strongly agree) } 4 \\
\text { (Strongly disagree) }\end{array}$ \\
\hline & $\begin{array}{l}\text { Would you say you are doing, more than enough, just } \\
\text { enough, or not enough to support [child] to: }\end{array}$ & \\
\hline $16-19$ & $\begin{array}{l}\text { Do (his/her) homework. Not skip school. Get involved } \\
\text { in positive activities outside of school (e.g. religious }\end{array}$ & $\begin{array}{l}1 \text { (More than enough) } 3 \\
\text { (Not enough) }\end{array}$ \\
\hline
\end{tabular}
activities, sports etc). Stay in school until he/she graduates from secondary school. 
TABLE 2 Continued

\begin{tabular}{|c|c|c|}
\hline & Items & Response Codes \\
\hline & \multicolumn{2}{|l|}{ Models Risk (Cronbach's alpha = 0.73) } \\
\hline $1-8$ & $\begin{array}{l}\text { Have any of your brothers or sisters ever had } \\
\text { premarital sex? Have any of your brothers or sisters } \\
\text { ever smoked or do any currently smoke cigarettes?, } \\
\text { Have any of your brothers or sisters ever drunk or do } \\
\text { any currently drink alcohol?, Have you ever lived } \\
\text { with anyone who was a problem drinker or } \\
\text { alcoholic?, Have you witnessed your mother/mother } \\
\text { figure being beaten?, Do you know of any close } \\
\text { friends who have kissed or been kissed?, Do you } \\
\text { know of any close friends who have fondled or been } \\
\text { fondled?, Do you know of any close friends who } \\
\text { have had sexual intercourse? }\end{array}$ & 1 (Yes), 2 (No) \\
\hline $9-10$ & $\begin{array}{l}\text { Drinking and drug use is a problem at my school, } \\
\text { Teachers in my school try to have sex with pupils } \\
\text { and sometimes do have sex with them }\end{array}$ & $\begin{array}{c}1 \text { (Strongly agree) } 5 \\
\text { (Strongly disagree) }\end{array}$ \\
\hline \multirow[t]{2}{*}{$11-15$} & $\begin{array}{l}\text { How many of your friends get into trouble at school } \\
\text { (e.g. disciplinary action, get into fights etc)? How } \\
\text { many of your friends drink alcohol? Run away from } \\
\text { home? Get into trouble with the police? Have sexual } \\
\text { intercourse? }\end{array}$ & $\begin{array}{l}1 \text { (None of them) to } 4 \\
\text { (All of them) }\end{array}$ \\
\hline & Vulnerability Risk (Cronbach's alpha $=0.83$ ) & \\
\hline $1-3$ & $\begin{array}{l}\text { How well do you get along with others your age? How } \\
\text { well do you live up to what other people expect of } \\
\text { you? What about your ability to do well in school } \\
\text { (even if you are not in school currently)? }\end{array}$ & $\begin{array}{l}1 \text { (Very well) to } 4 \text { (Not } \\
\text { well at all) }\end{array}$ \\
\hline 4 & How attractive do you think you are? & $\begin{array}{l}1 \text { (Very attractive) to } 4 \\
\text { (Not attractive at all) }\end{array}$ \\
\hline 5 & On the whole, how satisfied are you with yourself? & $\begin{array}{l}1 \text { (Very satisfied) to } 4 \\
\text { (Not satisfied at all) }\end{array}$ \\
\hline 6-15 & $\begin{array}{l}\text { What are the chances that you will finish primary } \\
\text { school? What are the chances that you will join } \\
\text { secondary school? Finish secondary school? Go to } \\
\text { university?, have a job that pays well?, be able to } \\
\text { own your own home?, have job that you enjoy } \\
\text { doing?, have happy family?, stay in good health } \\
\text { most of the time?, be respected in your community? }\end{array}$ & 1 (High) 3 (Low) \\
\hline
\end{tabular}

assess the linear relationships among the theoretical predictors as well as with the problem behavior outcome measure, correlation coefficients were computed. The outcome and theoretical predictors were assessed for the assumptions of normality. The MPBI measure was skewed to the right and a natural log transformation of $(\mathrm{MPBI}+1)$ was applied to normalize the distribution of this outcome. Hierarchical linear regression methods were then used to assess the applicability of Problem Behavior Theory by modeling the relation of the theoretical predictors, as well as their interactions, to the log-transformed MPBI outcome measure. First, the logtransformed MPBI outcome measure was fitted by including only the sociodemographic variables as predictors. A second model was fitted by including the 
socio-demographic variables (as controls) and then adding the four protective factor composite measures. A third model was fitted by now adding the two risk factor composite measures to the first model. Finally, a fourth model was fitted by adding all significant interactions between the four protective and the two risk factor composite measures to the third model. These four models were fitted separately for the two age cohorts. The results were then back-transformed to reflect the true relationship between the predictor measures and MPBI that are presented in the tables.

\section{RESULTS}

Results are presented first for the bi-variate relations among the explanatory measures and for their relations to the problem behavior outcome measure, the MPBI. Next, results for the multi-variate analyses are described, controlling for one's socio-demographic characteristics. Finally, the findings about interactions or moderator effects of protection on the impact of exposure to risk are presented.

\section{Examining the Applicability of Problem Behavior Theory: Bi-Variate Analyses}

Before examining whether the multi-variate explanatory model of Problem Behavior Theory applies to adolescents living in the slum settlements in Nairobi City, we computed bi-variate correlations to establish the relationships of the predictor measures with the problem behavior outcome variable, the Multiple Problem Behavior Index. Correlations are presented separately for each age cohort (Table 3 ). As expected, nearly all four protective factors were positively correlated with each other in both age cohorts except for support protection and models protection (MP) among the young cohort (negative but not significant). Similarly, positive correlations were observed for the two risk factor measures, and the correlations were negative between the protective and the risk factor measures. All of these correlations were significant in the older cohort, and most were significant in the younger cohort. As also expected, and in both age cohorts, the four protective factors were significantly and negatively correlated with the MPBI while the two risk factor measures, models risk and vulnerability risk, were significantly and positively correlated with the MPBI.

Among the older cohort, the magnitudes of the coefficients for all four protective factors and for the two risk factors were considerably larger than those observed among the younger cohort. Overall, the bi-variate results provide strong support for the problem behavior conceptual framework.

\section{Examining the Applicability of Problem Behavior Theory: Multi-Variate Analyses}

To test the Problem Behavior Theory explanatory model of adolescent problem behavior involvement, four regression models were fitted separately for each of the two age cohorts, with the log-transformed MPBI measure as the outcome variable, and the four protective factors, and the two risk factors as independent predictors while controlling for socio-demographic characteristics. The back-transformed results from the fitted models, including those that add in the significant interactions between the protective and risk factors are presented in Table 4. In Models 1 and 5, only the socio-demographic measures were fitted; these accounted for $5.8 \%$ of the variance in the MPBI among the adolescents aged 12-14 years, and for $12.4 \%$ of the variance in the MPBI for the older cohort. In both age cohorts, the negative gender 


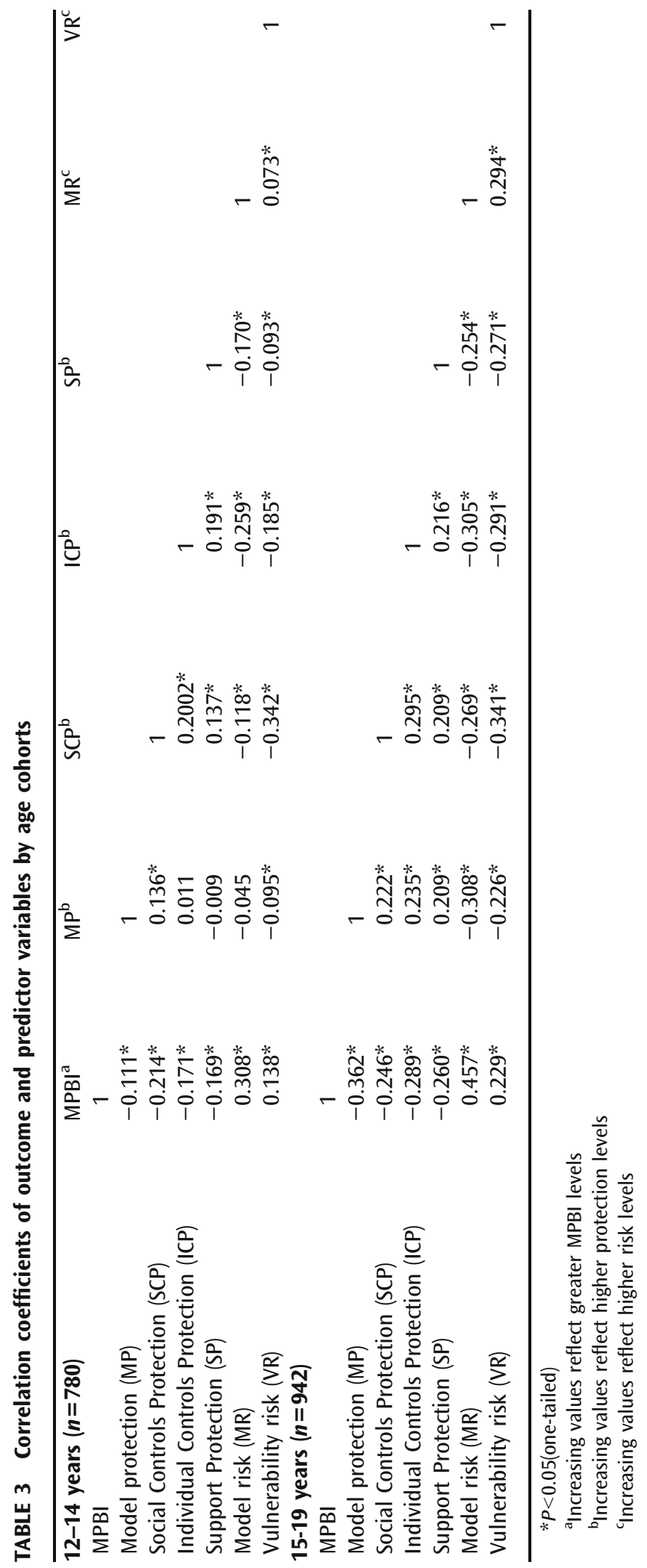


coefficients indicate that females were significantly less likely to be involved in multiple problem behaviors. Multiple problem behavior involvement increased with increasing age as seen from the positive significant coefficients for age in both age cohorts. In addition, adolescents who lived alone or with other relatives or nonrelated members were more likely to be involved in multiple problem behaviors. Duration of stay and an educational level higher than primary among older adolescents only, were associated with increased and decreased involvement in problem behavior, respectively.

In Models 2 and 6, all four protective factor measures were added to the sociodemographic measures. This yields an increase in variance accounted for in MPBI of $5.3 \%$ for the younger cohort and of $15.1 \%$ for the older cohort, a much larger contribution for the latter. When the two risk factor measures were added in Models 3 and 7, variance accounted for increased by $7.5 \%$ and $6.7 \%$ for the younger and older cohorts, respectively. Finally, the full theoretical Models 4 and 8 , which add the significant interactions, yield additional increments in variance that accounted for $1.2 \%$ for the $12-14$ year olds and for $2.2 \%$ for the $15-19$ year olds. The final $r$ squares are highly significant, with $19.8 \%$ of variance in MPBI accounted for in the younger cohort, and $36.4 \%$ of variance accounted for in the older cohort.

In the final models for both age cohorts (Models 4 and 8, Table 4), the coefficients of all four protective factors were negative as expected, although nonsignificant for individual controls protection (ICP) among the younger adolescents, and for social controls protection (SCP) among the older adolescents. Similarly, in both age cohorts, the two risk factors had positive coefficients, as expected, with strong significant effects observed for the models risk (MR) composite measure. The vulnerability risk composite measure (VR) was not significant for either cohort.

It is of interest to compare the unique variance accounted for by the protective factors and by the risk factors separately because it may have implications for interventions that focus on enhancing protection versus those that seek to reduce risk. Since the protective factors and the risk factors share common variance, when the four protective factors enter the regression equation in Models 2 and 6, they "capture" all the shared variance; thus, the increment in variance accounted for of $5.3 \%$ for the younger cohort and of $15.1 \%$ for the older cohort over Models 1 and 5 reflects both the unique variance of the protective factors and the variance they share with the risk factors. The unique variance of the two risk factors is shown by the increment in variance accounted for in Models $3(7.5 \%)$ and $7(6.7 \%)$ for the younger and older groups, respectively, since the shared variance was already taken up by the protective factors in the preceding models. In order to determine the unique variance of the four protective factors, additional regressions were run in which the protective factors entered the regression equation after the risk factors. These alternative Models 3 and 7 (not shown; available from the authors) indicate that the unique variance for the protective factors is $1.8 \%$ and $5.7 \%$ for the younger and older cohorts, respectively.

\section{Examining Protection-by-Risk Interactions or Moderator Effects of Protection}

In order to assess the moderator effects of protection on the association of risk to the adolescent MPBI, all eight protection-by-risk interaction terms were included in Models 4 and 8 . Non-significant interactions at the 5\% level were later dropped, and those models were re-fitted with only the significant interactions. The final 
models (4 and 8 ) for both age cohorts are shown in Table 4. There were two significant interactions out of the eight for the younger cohort, and three out of the eight for the older cohort. In both age cohorts, MP significantly moderated the relation of $\mathrm{MR}$ to the $\mathrm{MPBI}$. The moderating effect of MP on the relationship between MR and the back-transformed MPBI is illustrated in Figs. 1 and 2 for the younger and the older cohorts, respectively.

For both age cohorts, the moderating effect of MP on the relationship between MR and MPBI is evident. The relation of MR to the MPBI is strong when models protection is low, but when models protection is high, the relation of MR to the MPBI is much weaker. This is illustrated by the smaller difference between the High and Low risk groups under high protection than under low protection. In addition to the interactions illustrated in Figs. 1 and 2, there was also a significant moderator effect of MP on the relation of vulnerability risk to the MPBI in the younger adolescent cohort. Among younger adolescents, high vulnerability was more likely to be related to problem behavior involvement under low MP than under high MP. Finally, for older adolescents, there was a negative moderator effect of individual controls protection on vulnerability risk as theoretically expected, and a positive moderator effect of support protection on MR. The latter direction, theoretically unexpected, indicates that high support protection enhances the relation of MR to the MPBI, a finding that may reflect that support protection is mainly coming from peer models. The evidence of significant interactions or moderator effects provides further support for the applicability of Problem Behavior Theory and indicates that protection can have both direct and buffering effects on exposure to risk.

\section{DISCUSSION}

The current study investigated the applicability of Problem Behavior Theory in explaining engagement in multiple problem behaviors among adolescents living in two slum settlements in Nairobi, Kenya. The psychosocial protective and risk factors of the theory provided a substantial and informative account of variation in adolescent problem behavior among both younger and older cohorts of adolescents in the Nairobi slum settlements. Controlling for the social demographic variables, the theoretical measures alone accounted for $14 \%$ of variance in the MPBI in the younger cohort, and for $24 \%$ in the older cohort. These findings show that even within slum areas, there is ample variation in problem behavior that can be accounted for significantly by the psychosocial constructs of Problem Behavior Theory. This application of the theory in a developing country in subSaharan Africa has demonstrated its generality and appropriateness beyond the United States and other Western societies (see also Jessor ${ }^{11}$ ). The results of the study add to the sparse literature on problem behavior among poor urban youth in developing countries.

Among the younger adolescents, significant associations were observed for the models protection, social controls protection, and support protection measures and for the measure of models risk. For the older adolescents, significant coefficients were observed for models protection, individual controls protection, support protection, and models risk. This consistency across both age cohorts is noteworthy. The measures of models protection and models risk were much stronger predictors of variation in problem behavior in both age cohorts than socio-demographic factors, with models risk positively associated with the MPBI and models protection 


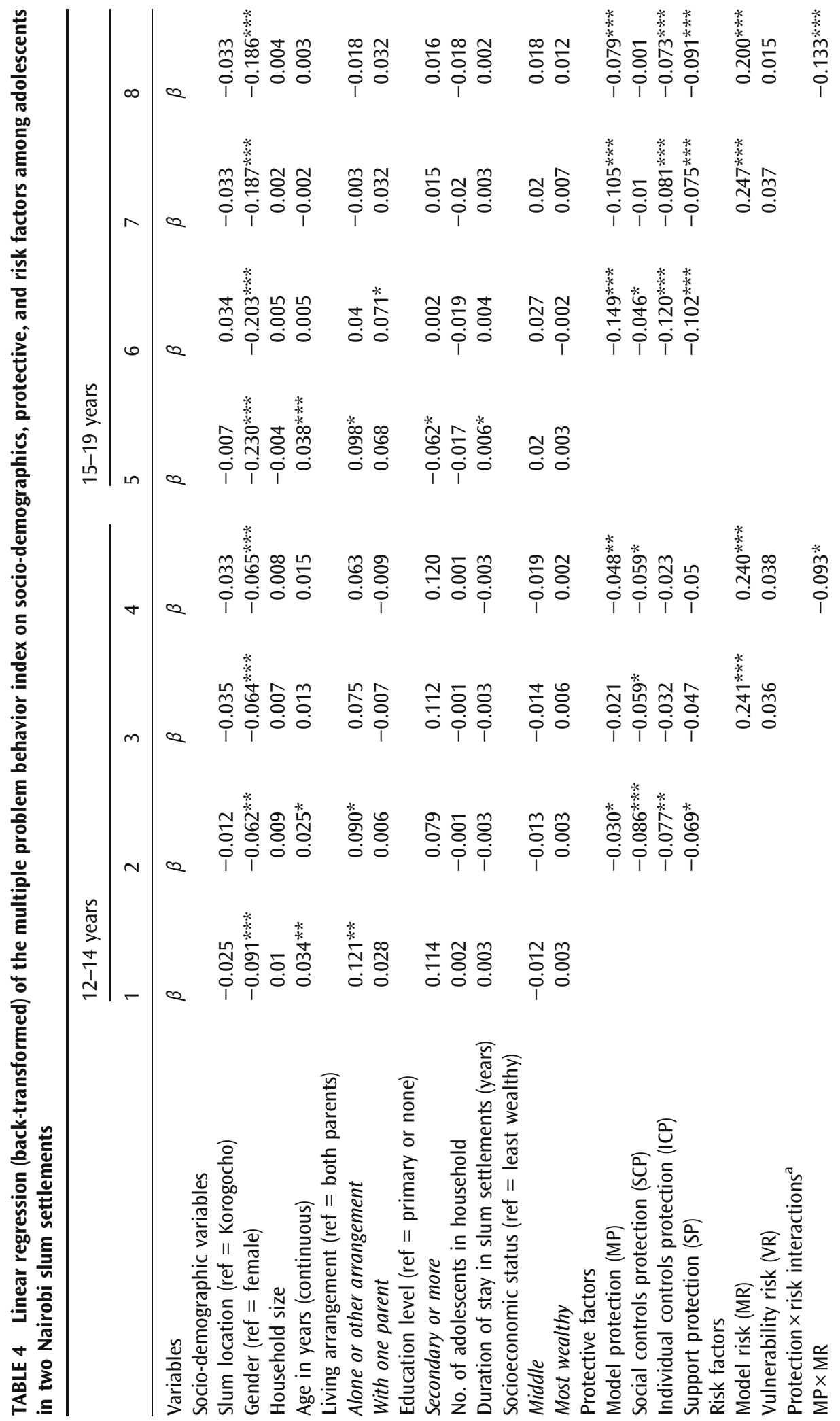




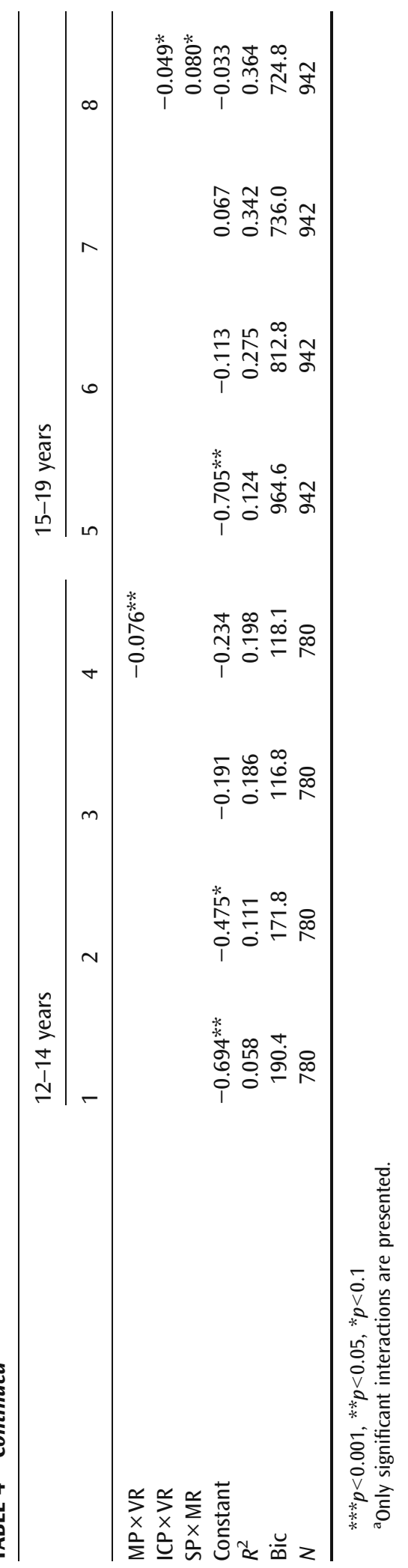




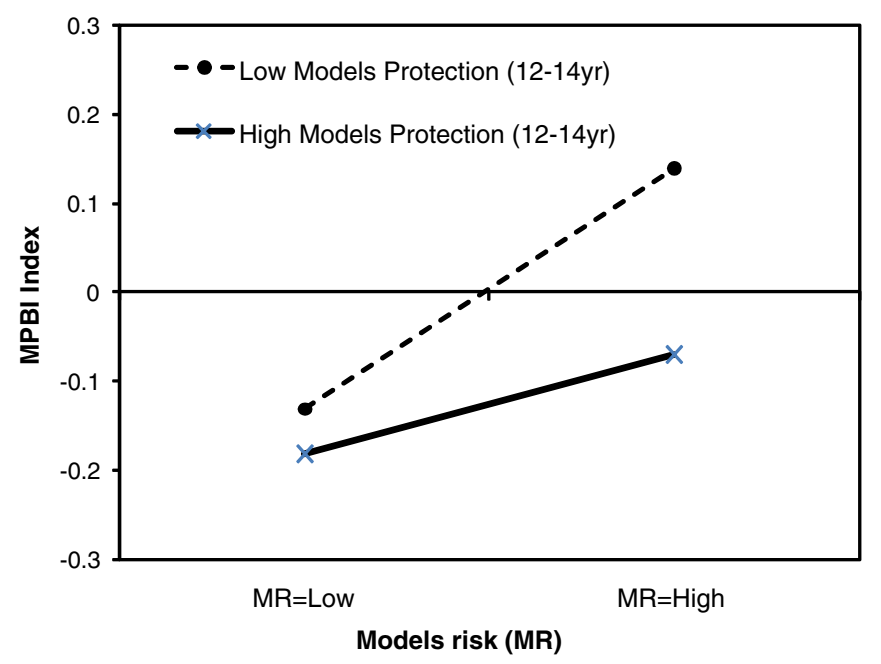

FIGURE 1. Moderator effects for MP on the relationship of MR to the MPBI among 12-14-year-old adolescents.

negatively associated with the MPBI, both as theoretically expected. Overall, the evidence supports the theoretical concepts of models (both protection and risk), controls (both individual and social), supports, and vulnerability and it points to them as targets of intervention for programs designed to ameliorate the impact of the urban slum context on adolescent health and development.

The finding of significant interactions or moderator effects in this study provides further support for the usefulness of Problem Behavior Theory and is noteworthy because of the well-known difficulty of demonstrating interaction effects in field studies. $^{29}$ Models protection was shown to moderate models risk in both age cohorts, and models protection also moderated vulnerability risk among younger

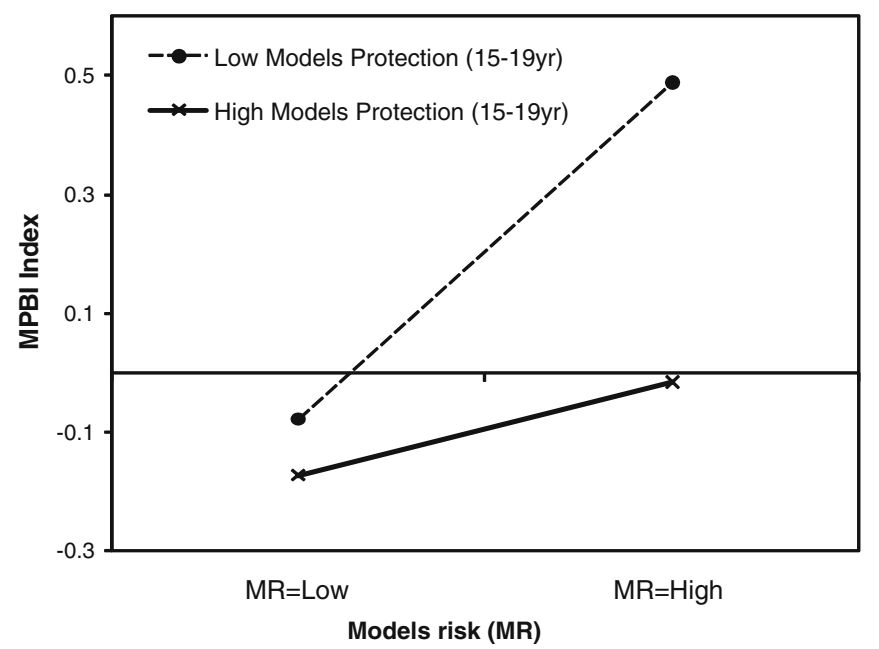

FIGURE 2. Moderator effects for MP on the relationship of MR to the MPBI among 15-19-year-old adolescents. 
adolescents. The moderating effect of models protection on the association between vulnerability and MPBI among younger adolescents indicated that at low levels of vulnerability, adolescents with low levels of models protection have about the same likelihood of involvement in problem behavior as their peers with high models protection. At high levels of vulnerability, however, adolescents with high levels of models protection show less involvement in problem behavior than their peers with low levels of models protection.

Another moderator effect, individual controls protection moderating vulnerability risk among the older adolescents, was of interest. Strong individual controls protection, such as a strong belief in the importance of finishing secondary school, or religiosity, or the ability to resist peer pressure, lessened the likelihood that adolescents with high vulnerability (low perceived life chances or low self-esteem) would engage in multiple problem behaviors. However, the finding that the moderating effect of support protection was to enhance the relation of models risk to the MPBI in the older cohort was in the theoretically unexpected direction. Support protection at the bi-variate level was negatively associated with the MPBI in both age cohorts, as theoretically expected. This finding may suggest, therefore, that the primary source of support protection is from peers, who also are the main source of models risk.

The findings about the unique variance of the protective versus the risk factors cannot ignore the fact that protection was measured by four measures while risk was measured by only two. Nevertheless, it is worth discussing the relative importance of protection and risk and their implications for intervention and prevention programs. Among young adolescents, the unique variance for risk factors $(7.5 \%)$ was greater than for protective factors $(1.8 \%)$, signaling that programs need to emphasize risk reduction while also strengthening protection. For older adolescents, a marginal difference between the unique variance accounted for by protective $(5.7 \%)$ and risk $(6.7 \%)$ factors was observed suggesting that equal weight be given to both risk reduction and protection enhancement efforts. A similar result was observed among US and Chinese adolescents, where researchers examined the relative importance of protection versus risk factors as determinants of problem behaviors and found that both had relevant influences. ${ }^{6}$

The socio-demographic measures, such as slum location, household size, number of adolescents in the household, and socioeconomic status, accounted for only limited amounts of variance in problem behavior involvement. Since the samples were all drawn from within slum areas, this is not surprising, and those measures might be expected to be more influential in studies comparing slum with non-slum contexts. However, being male, and living alone or with neither biological parent, were both associated with an increase in problem behavior involvement. The observed differences in adolescent problem behaviors due to differences in parental living arrangements highlights the importance of having parental monitoring and support, and limiting the effects of parental deprivation in these urban communities where other family-related social networks may not be available to young adolescents. These findings are consistent with previous research that found parental monitoring to be associated with lower levels of delinquent behavior, greater schooling performance, and lower levels of sexual behavior. ${ }^{30,32}$ The findings have implications for programming for successful adolescent transition to adulthood in resource limited settings. Presence of parents or guardians and a friendly home environment are a key starting point for encouraging better communication between adults or siblings who act as advisers 
or role models to adolescents in settings where the traditional extended family network has been weakened. The significant influence of models risk whether in the classroom or with older siblings in the family or older peers in the neighborhood requires individual and community level programming that recognizes the linkages between risk behaviors and capitalizes on adolescent's positive potential. Equally, knowledge contributions from influential social settings and adolescent networks that go beyond homes, such as schools, churches, and clubs are key areas that can be improved and strengthened.

There are, of course, several study limitations that warrant acknowledgment. First, as a cross-sectional study, it is limited in making inferences about causal direction in the relationships observed. Toward that end, subsequent data waves assessing later development will be required. In addition, the data employed are all self-reported and therefore subject to possible bias in the direction of socially and culturally desirable responding. Problem behaviors can, of course, be influenced by many social-structural factors that we were unable to measure in the current study such as limited opportunity, corruption, poor schooling and teacher absenteeism, community disorganization, and other social and environmental factors. Finally, some of the behavior measures were based on dichotomous items assessing involvement versus non-involvement rather than assessing intensity of involvement which would yield greater variation.

Despite these limitations, the study has advanced understanding of adolescent problem behavior in the informal settlements around a rapidly urbanizing city in a sub-Saharan African context. In so doing, it has documented the generality and appropriateness of a particular conceptual framework, Problem Behavior Theory, and it has identified protective and risk factors that can constitute targets for intervention programs to better the lives of young people in the developing world and facilitate a healthier transition to adulthood.

\section{ACKNOWLEDGMENTS}

The Transitions-To-Adulthood study is part of a larger project on Urbanization, Poverty and Health Dynamics, that is funded by the Wellcome Trust (Grant Number GR $07830 \mathrm{M}$ ). Funding for the Education Research Project was provided by the William and Flora Hewlett Foundation (Grant Number 2004-4523). The authors' analysis and writing time is supported by funding from the Wellcome Trust (Grant Number GR $07830 \mathrm{M}$ ), the William and Flora Hewlett Foundation (Grant Number 2006-8376) and the Rockefeller Foundation (Grant Number 2007-HE 008). We are grateful to the colleagues at APHRC for their contributions and the adolescents in the study communities for participating in this study.

\section{REFERENCES}

1. Jessor R, Jessor SL. Problem Behavior and Psychosocial Development: A longitudinal Study of Youth. New York: Academic; 1977. Pp xv+281.

2. Jessor R. Problem-behavior theory, psychosocial development, and adolescent problem drinking. Br J Addict. 1987; 82(4): 331-342.

3. Williams JH, Ayers CD, Abbott RD, Hawkins JD, Catalano RF. Structural equivalence of involvement in problem behavior by adolescents across racial groups using multiple group confirmatory factor analysis. Soc Work Res. 1996; 20: 168-177. 
4. Hawkins JD, Lishner D, Catalano RF, Howard M. Childhood predictors of adolescent substance abuse: toward an empirically grounded theory. J Child Comtemp Soc. 1986; 8: 11-48.

5. Jessor R, Donovan JE, Costa FM. Beyond Adolescence: Problem Behavior and Young Adult Development. New York: Cambridge University Press; 1991. Pp.xv +312.

6. Jessor R, Turbin MS, Costa FM, Dong Q, Zhang H, Wang C. Adolescent problem behavior in China and the United States: a cross-national study of psychosocial protective factors. J Res Adolescence. 2003; 13(1): 329-360.

7. Turbin MS, Jessor R, Costa FM, Dong Q, Zhang H, Wang C. Protective and risk factors in health-enhancing behavior among adolescents in China and the United States: does social context matter? Health Psychol. 2006; 25(4): 445-454.

8. Vazsonyi AT, Trejos-Castillo E, Huang L. Risky sexual behaviors, alcohol use, and drug use: a comparison of Eastern and Western European adolescents. J Adolesc Health. 2006; 39(5): 753.e1-753.e11.

9. Jessor R. Risk behavior in adolescence: a psychosocial framework for understanding and action. J Adolesc Health. 1991; 12(8): 597-605.

10. Donovan JE, Jessor R, Costa FM. Adolescent problem drinking: stability of psychosocial and behavioral correlates across a generation. J Stud Alcohol. 1999; 60(3): 352-361.

11. Jessor R. Description versus explanation in cross-national research on adolescence. $J$ Adolesc Health. 2008; 43(6): 527-528.

12. Vazsonyi AT, Chen P, Young M, et al. A test of Jessor's problem behavior theory in a Eurasian and a Western European developmental context. J Adolesc Health. 2008; 43(6): 555-564.

13. United Nations Human Settlement Programme (UN-HABITAT). The State of African Cities 2008-A Framework for Addressing Urban Challenges in Africa. Nairobi: UNHABITAT; 2008.

14. African Population and Health Research Center (APHRC). Population and Health Dynamics in Nairobi's Informal Settlements. Nairobi, Kenya: APHRC; 2002.

15. United Nations Human Settlement Programme (UN-HABITAT). The Challenges of Slums: Global Report on Human Settlements. Nairobi: UN-HABITAT; 2003.

16. African Population and Health Research Center (APHRC). The Economic, Health, and Social Context of HIV Infection in Informal Urban Settlements of Nairobi. Nairobi, Kenya: APHRC; 2009.

17. Kenya Government and ORC Macro. Kenya Demographic and Health Survey 2003. Nairobi, Kenya: Central Bureau of Statistics and Ministry of Health; 2004.

18. Mugisha F. School enrollment among urban non-slum, slum and rural children in Kenya: is the urban advantage eroding? Intern J Educ Dev. 2006; 26(5): 471-482.

19. Mugisha F, Arinaitwe-Mugisha J, Hagembe BON. Alcohol, substance and drug use among urban slum adolescents in Nairobi Kenya. Cities. 2003; 20(4): 231-240.

20. Dodoo FN, Zulu EM, Ezeh AC. Urban-rural differences in the socioeconomic deprivation-sexual behavior link in Kenya. Soc Sci Med. 2007; 64(5): 1019-1031.

21. Zulu EM, Dodoo FN, Ezeh AC. Sexual risk-taking in the slums of Nairobi, Kenya, 19938. Popul Stud (Camb). 2002; 56(3): 311-323.

22. Zulu EM, Dodoo FN, Ezeh AC. Urbanization, Poverty and Sex: Roots of Risky Sexual Behaviors in Slum Settlements in Nairobi, Kenya. In: Kalipeni E, Oppong J, Craddock S, Ghosh J, eds. HIV and AIDS in Africa: Beyond Epidemiology. Malden, MA: Blackwell; 2003: 167-174.

23. Asiimwe-Okiror G, Opio AA, Musinguzi J, Madraa E, Tembo G, Carael M. Change in sexual behaviour and decline in HIV infection among young pregnant women in urban Uganda. AIDS. 1997; 11(14): 1757-1763.

24. Kilian AH, Gregson S, Ndyanabangi B, et al. Reductions in risk behaviour provide the most consistent explanation for declining HIV-1 prevalence in Uganda. AIDS. 1999;13 (3):391-398. 
25. African Population and Health Research Center (APHRC). Health and Livelihood Needs of Residents of Informal Settlements in Nairobi City. Nairobi, Kenya: APHRC; 2002.

26. African Population and Health Research Center (APHRC). Handbook for Analysis of ERP Data-Version 1.1. Nairobi, Kenya: APHRC; 2006.

27. Filmer D, Pritchett L. Estimating wealth effects without expenditure data-or tears: an application to educational enrollments in States of India. Demography. 2001; 38(1): 115132.

28. Stata Version 10 Statistical Software [computer program]. Version 10. Texas, USA: StataCorp LP; 2008.

29. McClelland GH, Judd CM. Statistical difficulties of detecting interactions and moderator effects. Psychol Bull. 1993; 114(2): 376-390.

30. Jacobson KC, Crockett LJ. Parental monitoring and adolescent adjustment: an ecological perspective. J Res Adolescence. 2000; 10: 65-97.

31. Sampson RJ, Laub JH. Urban poverty and the family context of delinquency: a new look at structure and process in a classic study. Child Dev. 1994; 65: 523-540.

32. Kumi-Kyereme A, Awusabo-Asare K, Biddlecom AE, Tanle A. Influence of social connectedness, communication and monitoring on adolescent sexual activity in Ghana. Afr J Reprod Health. 2007; 11(3): 133-149. 